\title{
PROTECCIÓN DE LA VÍCTIMA, CUATRO CRITERIOS DE LA CORTE INTERAMERICANA DE DERECHOS HUMANOS: INTERPRETACIÓN EVOLUTIVA, AMPLIACIÓN DEL CONCEPTO DE VÍCTIMA, DAÑO AL PROYECTO DE VIDA Y REPARACIONES
}

\author{
LILIANA GALDÁMEZ ZELADA*
}

RESUMEN: El trabajo analiza la jurisprudencia de la Corte Interamericana de Derechos Humanos ${ }^{1}$ y sus aportes para la mejor y mayor protección de la víctima de una violación a los derechos humanos. El documento se centra en el estudio de: criterios de interpretación; ampliación del concepto de víctima; daño al proyecto de vida y las medidas de reparación que imponen a los Estados obligaciones positivas o de hacer.

Los criterios de la Corte se fundan en la preocupación por el ser humano y la protección de su dignidad. Uno de los elementos que define el contenido de los derechos humanos es su carácter progresivo, ya que en sus orígenes su reconocimiento ha sido concebido como un derecho mínimo además de irreversible. La Corte Interamericana ha empleado el carácter progresivo no solo cuando ha mejorado el estándar de protección de un derecho, también, en la construcción de nuevos mecanismos jurídicos para el amparo de las víctimas. Varios de estos criterios son compartidos por el Tribunal Europeo de Derechos Humanos².

Palabras clave: Jurisprudencia Corte Interamericana de Derechos Humanos, víctima, protección.

ABSTRACT: This paper analyzes Interamerican Court of Human Rights jurisprudence and its contributions to protect victims of human rights violations. The document focuses on the study of: interpretation criteria; enlargement of victim's concept; life project damage and measures of reparation that imposes States positive obligations.

The Court criteria are founded on the concern for human being and protection of his dignity. One defines elements that the content of the human rights is his progressive character, since in his origins has been conceived as an irreversible, minimal human right. The Interamerican Court has used the progressive character not only when it has improved the protection standard of a human right, but also in the construction of new juridical protection victim's mechanisms. Several of these criteria are shared by the European Court of Human rights.

Key words: Jurisprudence, Interamerican Court of Human Rights, victim, Human rights protection.

\footnotetext{
* Abogada, candidata a doctora por la Universidad de Valladolid, en la actualidad, consultora en la Oficina Regional para América Latina y el Caribe del Alto Comisionado de Naciones Unidas para los Derechos Humanos. También investigadora del Centro de Estudios Constitucionales Universidad de Talca. lilianaandrea.galdamez@alumnos.uva.es

${ }^{1}$ En adelante, Corte Interamericana, la Corte, o Corte IDH.

${ }^{2}$ En adelante, TEDH, Tribunal Europeo o Tribunal de Estrasburgo.
} 


\section{INTRODUCCIÓN}

Luego de más medio siglo de desarrollo del derecho internacional de los derechos humanos, en los albores del s. XXI, las violaciones masivas a los derechos humanos se convierten en cruel paradigma de nuestros tiempos. Debemos destacar, no obstante lo dicho, que en América Latina se ha superado la etapa más oscura de este fenómeno por lo que, de momento, el esfuerzo en la región se centra en la persecución y castigo de los hechos ocurridos en nuestro pasado reciente.

Frente a las masivas violaciones a los derechos humanos y a la impunidad que suele acompañarlas, el trabajo jurisprudencial de los tribunales internacionales de derechos humanos, la Corte Interamericana y el Tribunal Europeo abren nuevas perspectivas. Mediante la construcción de criterios, algunos ya recepcionados en los ordenamientos internos como la imposibilidad de aplicar amnistías, prescripciones e indultos a las más graves violaciones a los derechos humanos, se intenta superar los obstáculos que por años han dificultado la investigación de los hechos ${ }^{3}$ y la protección de la víctima. Entre los muchos aportes verificados a lo largo de estos años, queremos hacer mención a algunos asuntos menos abordados por la doctrina y la jurisprudencia comparada, dado que es posible prever que en el futuro alguno de ellos también tenga cabida o sea debatido en el ámbito del derecho interno.

La Corte Interamericana ha señalado que entre sus principales preocupaciones se encuentra la protección de la víctima y la reparación del daño. La mejor protección es impulsada por la aplicación de especiales criterios de interpretación y se refleja en la ampliación de las categorías de daño a través de la noción del daño al proyecto de vida; en el desarrollo del concepto de víctima, que se extiende a los familiares en casos de violación al derecho a la vida o integridad personal; y que en cuanto a las reparaciones se expresa en lo que la Corte ha denominado "otras medidas de reparación" cuyo objeto es a la vez que reparar a la víctima, ser una suerte de garantía de no repetición de los actos y que genera para los Estados obligaciones positivas, o de hacer.

\section{A. LA VÍCTIMA DE LA VIOLACIÓN}

La especial naturaleza de la jurisdicción ejercida por la Corte, que busca establecer responsabilidades institucionales, no penales, por la violación a los derechos humanos, ha desdibujado en algún sentido la atención hacia el sujeto activo o autor de la violación y ha dado una mayor relevancia a la figura de la víctima. La Corte ha asumido un rol especialmente activo para su protección y reparación, y en la valoración del daño tendrá una especial preocupación.

\footnotetext{
${ }^{3}$ En casos de desaparición forzada, la Corte ha dicho: "Como este Tribunal ha expresado reiteradamente, en casos de desaparición forzada la defensa del Estado no puede descansar en la imposibilidad del demandante de allegar prueba al proceso, dado que, en dichos casos, es el Estado quien detenta el control de los medios para aclarar los hechos ocurridos bajo su jurisdicción y por ello se depende, en la práctica, de la cooperación del propio Estado para la obtención de las pruebas necesarias...". Caso Bámaca Velásquez vs. Guatemala (2000) párrafos 152-153.
} 
A modo de introducción, queremos citar al juez Cançado Trindade en su voto razonado del caso Tibi vs. Ecuador ${ }^{4}$, donde analiza lo que denomina "La Posición Central de los Victimados en el Orden Jurídico", a cuya amplia dimensión ha contribuido el Derecho Internacional de los Derechos Humanos ${ }^{5}$; antes de adentrarnos en el análisis del fallo queremos, brevemente, referirnos a los hechos de la causa:

En este caso, la víctima era un comerciante de piedras preciosas, fue arrestado sin orden judicial y recluido en una cárcel donde fue detenido por 28 meses. La Corte consideró probado que durante su detención el Sr. Tibi fue sometido a sesiones de violencia física que buscaban obtener una autoinculpación, que "recibió golpes de puño en el cuerpo y en el rostro, quemaduras en las piernas con cigarrillos y descargas eléctricas en los testículos. En una ocasión fue golpeado con un objeto contundente y en la otra se le sumergió la cabeza en un tanque de agua"6. Que dichos actos produjeron en la víctima graves sufrimientos, tanto físicos como mentales. Considera que estos actos tenían por objeto "disminuir sus capacidades físicas y mentales y anular su personalidad para que se declarara culpable de un delito"7. Asimismo, consideró probado que fue sometido a amenazas y hostigamientos que le produjeron pánico y miedo por su vida. En cuanto a las condiciones de la prisión, la Corte estableció que el Sr. Tibi fue encarcelado en un lugar de gran hacinamiento, sin luz natural, sin ventilación, al principio de su detención sin cama, sin condiciones de higiene, aislado y con restricciones en sus regímenes de visita, por lo que estimó, le fue vulnerado su derecho a la integridad personal. La Corte reiteró que el Estado debe proveer condiciones mínimas para ser compatibles con la dignidad de los detenidos y que no se vean vulnerados otros derechos. Por otra parte, mientras duró su detención no recibió atención médica suficiente pese a haber sido examinado en dos oportunidades, constatándose lesiones (heridas y traumatismos), las que posteriormente no recibieron tratamientos y sin que los hechos fueran debidamente investigados. Por su parte, la Comisión agregó que la víctima no tuvo oportunidad de interponer recurso contra los malos tratos recibidos durante su detención, sin que además existiera en Ecuador un recurso "rápido y sencillo" que pudiera interponer ante el Tribunal competente para protegerse de la violación a sus derechos fundamentales contraviniendo el artículo 2 de la Convención Americana.

En este caso el juez Cançado destaca que en este ámbito la víctima efectivamente trasciende a la figura del "sujeto pasivo del delito", ya que "asume el rol de auténtico

\footnotetext{
${ }^{4}$ La Comisión presentó demanda a fin de determinar si el Estado violó los artículos 5 (Derecho a la Integridad Personal), 7 (Derecho a la Libertad Personal), 8 (Garantías Judiciales), 21 (Derecho a la Propiedad Privada) y 25 (Protección Judicial) de la Convención Americana, en conexión con el artículo 1 (Obligación de Respetar Derechos) en perjuicio de Daniel David Tibi. La Comisión agregó que la supuesta víctima no tuvo oportunidad de interponer recurso contra los malos tratos supuestamente recibidos durante su detención, sin que además existiera en Ecuador un recurso "rápido y sencillo" que pudiera interponer ante el Tribunal competente para protegerse de la violación a sus derechos fundamentales contraviniendo el artículo 2 de la Convención Americana. Corte IDH. Caso Tibi vs. Ecuador (2004). Serie C No 114. Sentencia de 7 de septiembre de 2004.

${ }^{5}$ En adelante DIDH.

${ }^{6}$ Caso Tibi vs. Ecuador (2004) párrafo 148.

7 Caso Tibi vs. Ecuador (2004) párrafo 149.
} 
sujeto activo de la acción judicial internacional en defensa de los derechos que le son inherentes como ser humano" ${ }^{8}$. Subraya la contribución del DIDH $^{9}$ en la restauración del papel central de la víctima, a diferencia del rol que ha jugado tradicionalmente en el ámbito del derecho penal (tanto nacional como internacional) orientado más hacia la figura del delincuente. Enfatiza, como resultado visible de su rol central, que la víctima sea considerada "sujeto activo de la acción internacional para la implementación de la responsabilidad del Estado por la lesión de sus derechos"10. Y agrega, "La protección de los victimados, y las reparaciones por los daños por ellos sufridos, constituyen su raison d'être. Este notable desarrollo... acarreó una verdadera transformación del propio orden jurídico internacional..."11.

\section{B. LOS CRITERIOS:}

\section{B.1. LA INTERPRETACIÓN EVOLUTIVA DE LOS INSTRUMENTOS INTERNACIONALES}

Las reglas de interpretación del DIDH son fundamentales para la práctica de los tribunales internacionales. En muchos tratados y convenciones abundan las normas vagas, probablemente como consecuencia de la resistencia de los Estados para asumir obligaciones claras y precisas en el ámbito internacional. Analizaremos los criterios generales de interpretación aplicados por la Corte Interamericana, que utiliza tanto reglas generales sobre interpretación de tratados propias del Derecho Internacional, como otras específicas del DIDH ${ }^{12}$.

En la sentencia sobre excepciones preliminares del caso Hilaire vs. Trinidad y Tobago de 2001, seguida contra el Estado por aplicar al Sr. Hilaire una pena de muerte obligatoria, y por tanto, "violar los derechos consagrados en los artículos: 4.1, 5.1, 5.2, 5.6, 7.5 y 25; todos en relación con el artículo 1.1 de la Convención"13, también por haber violado el artículo 2 de la Convención al no adoptar las medidas legislativas necesarias para hacer realmente efectivos los derechos y libertades establecidos en la Convención, la Corte señaló que esta Convención "se inspira en valores comunes superiores (centrados en la protección del ser humano), está dotada de mecanismos específicos de supervisión, se aplica de conformidad con la noción de garantía colectiva, consa-

\footnotetext{
${ }^{8}$ Caso Tibi vs. Ecuador (2004) voto razonado juez Cançado Trindade, párrafo 16.

${ }^{9}$ DIDH: Derecho internacional de los derechos humanos.

${ }^{10}$ Caso Tibi vs. Ecuador (2004) párrafo 17.

${ }^{11}$ Caso Tibi vs. Ecuador (2004) párrafo 19.

$12 \mathrm{~J}$. A. Carrillo Salcedo analiza las reglas de interpretación del Convenio por el Tribunal Europeo de Derechos Humanos, que ha expresado su opinión favorable a: la tendencia de autocontrol judicial frente a la doctrina del margen de apreciación de los Estados, así como manifestaciones favorables a la interpretación evolutiva y dinámica del Convenio Europeo. Respecto al primero, dice que el Tribunal ha "sido riguroso en el ejercicio de su competencia de control del margen de apreciación de los Estados, y que una importante línea jurisprudencial venga señalando que las limitaciones y restricciones del ejercicio de los derechos reconocidos no pueden atentar contra la substancia del derecho garantizado". CARRILLO SALCEDO (2003) p. 93.

${ }^{13}$ Corte IDH. Caso Hilaire vs. Trinidad y Tobago. Excepciones Preliminares. Serie C No 80 Sentencia de 1 de septiembre de 2001, párrafo 2 .
} 
gra obligaciones de carácter esencialmente objetivo y tiene una naturaleza especial, que la diferencia de los demás tratados, los cuales reglamentan intereses recíprocos entre los Estados partes y son aplicados por estos, con todas las consecuencias jurídicas que de ahí derivan en los ordenamientos jurídicos internacional e interno"14. La Corte consideró que los tratados modernos sobre derechos humanos tienen por objeto la protección de los derechos fundamentales de las personas, independientemente de su nacionalidad, no solo frente a su propio Estado, sino frente a cualquier Estado Parte, sometiéndose los Estados a un "orden legal dentro del cual ellos, por el bien común, asumen varias obligaciones, no en relación con otros Estados, sino hacia los individuos bajo su jurisdicción"15.

La sentencia cuenta con el voto razonado del juez Cançado Trindade, que señala: "La metodología de interpretación de los tratados de derechos humanos, desarrollada a partir de las reglas de interpretación consagradas en el derecho internacional (tales como las enunciadas en los artículos 31-33 de las dos Convenciones de Viena sobre Derecho de los Tratados, de 1969 y 1986), alcanza tanto las normas sustantivas (sobre los derechos protegidos) como las cláusulas que rigen los mecanismos de protección internacional" 16 .

Profundizando en los criterios de interpretación, en el caso de los Hermanos Gómez Paquiyauri vs. Perú, de 2004, seguido por la detención, tortura y posterior ejecución extrajudicial de Emilio Moisés y Rafael Samuel Gómez Paquiyauri de 14 y 17, años respectivamente, la Corte reitera que una persona ilegalmente detenida se encuentra en una situación agravada de vulnerabilidad que pone en riesgo que se afecten otros derechos, que pese a la brevedad de una detención ilegal ella sola configura una violación a los derechos humanos, que en esos casos es posible inferir o presumir que la víctima de una detención ilegal, además fue violentada en su derecho a la integridad, que cuando no median pruebas en sentido contrario dicha persona padeció un trato inhumano y degradante. Que además de ser arbitrariamente detenidos, para las víctimas no fue posible que operaran las salvaguardas establecidas en el artículo 7 de la Convención. La Corte IDH recuerda lo señalado por la Corte europea: el análisis de la gravedad de los actos constitutivos de violación a la integridad, es relativo, depende de las circunstancias del caso, su duración, efectos físicos y mentales, en algunos casos incide el sexo, la edad y el estado de salud de las víctimas.

En este caso la Corte consideró acreditado que durante su detención las víctimas recibieron maltrato físico y psicológico. Y que los hechos les infligieron graves sufrimientos físicos y mentales. Estas consideraciones unidas a la edad de los detenidos, le llevaron a calificar los actos como tortura.

En cuanto a los criterios de interpretación, la Corte señaló que cuando interpreta un tratado "no solo se toman en cuenta los acuerdos e instrumentos formalmente relacionados con este (inciso segundo del artículo 31 de la Convención de Viena), sino

14 Corte IDH. Caso Hilaire vs. Trinidad y Tobago (2001). Excepciones Preliminares. Serie C No 80 Sentencia de 1 de septiembre de 2001, párrafo 94.

${ }^{15}$ Caso Hilaire vs. Trinidad y Tobago (2001) párrafo 95.

${ }^{16}$ Caso Hilaire vs. Trinidad y Tobago (2001) voto razonado juez Cançado Trindade, párrafo 13. 
también el sistema dentro del cual se inscribe (inciso tercero del artículo 31). El Tribunal ha señalado anteriormente que esta orientación tiene particular importancia para el Derecho Internacional de los Derechos Humanos, el que ha avanzado sustancialmente mediante la interpretación evolutiva de los instrumentos internacionales de protección"17. La Corte consideró que la interpretación evolutiva se encuentra consagrada en las reglas generales de interpretación de la Convención de Viena de 1969, y afirma que tanto la Corte Interamericana como la Europea han dicho que "los tratados de derechos humanos son instrumentos vivos, cuya interpretación tiene que acompañar la evolución de los tiempos y las condiciones de vida actuales" ${ }^{18}$.

Otra opinión destacada sobre principios de interpretación, es la del juez Cançado en el voto razonado del caso Masacre Plan de Sánchez vs. Guatemala"19, donde se demandó al Estado por la violación a los derechos a la integridad personal, protección judicial, garantías judiciales, a la igualdad ante la ley, a la libertad de conciencia y religión y a la propiedad privada, en relación con la obligación de respetar derechos a los familiares y sobrevivientes de 268 personas, víctimas de una masacre, mayoritariamente indígenas mayas en la aldea Plan de Sánchez ejecutados por miembros del Ejército en 1982, masacre que permaneció, y aún permanece, en la impunidad y donde la Comisión estimó que el Estado no había investigado seriamente los hechos, ni juzgado ni sancio-

${ }^{17}$ La Comisión sometió a consideración de la Corte, si el Estado violó los artículos 4 (Derecho a la Vida), 5 (Derecho a la Integridad Personal), 7 (Derecho a la Libertad Personal) y 19 (Derechos del Niño) por las presunta detención, tortura y ejecución extrajudicial de los hermanos Emilio Moisés y Rafael Samuel Gómez Paquiyauri, así como los artículos 8 (Garantías Judiciales), art. 13 y 25 (Protección Judicial) de la Convención Americana, en perjuicio de sus familiares, todos en relación con la obligación establecida en el artículo 1.1 (Obligación de Respetar Derechos) de la misma. De igual manera solicitó a la Corte declarar la violación de los artículos 1, 6 y 8 de la Convención Interamericana para Prevenir y Sancionar la Tortura en perjuicio de los hermanos Gómez Paquiyauri, solicitó a la Corte que ordenara al Estado reparaciones pecuniarias y no pecuniarias.

Los hechos: en junio de 1991 en medio de operativos policiales, las víctimas de 14 y 17 años fueron detenidas por agentes de la Policía Nacional e introducidos en el maletero de un vehículo policial y supuestamente ejecutados en el trayecto posterior a su detención. Luego de una hora aproximada, los cuerpos fueron ingresados a la morgue. La Comisión alegó que los tribunales peruanos investigaron los hechos y determinaron la responsabilidad de los autores materiales y que aunque el autor intelectual fue identificado, por encontrarse prófugo de la justicia no fue juzgado ni sancionado. Agregó que los tribunales peruanos impusieron una reparación civil a los autores materiales que a la fecha de presentación de la demanda no había sido pagada a los familiares de las presuntas víctimas. Corte IDH. Caso de los Hermanos Gómez Paquiyauri vs. Perú (2004) párrafos 164-165.

${ }^{18}$ Caso de los Hermanos Gómez Paquiyauri vs. Perú (2004) párrafo 165.

${ }^{19} \mathrm{La}$ Comisión Interamericana sometió ante la Corte una demanda contra el Estado de Guatemala, con el fin de que declarara si el Estado violó los derechos a la integridad personal, protección judicial, garantías judiciales, a la igualdad ante la ley, a la libertad de conciencia y religión y a la propiedad privada en relación con la obligación de respetar derechos a los familiares y sobrevivientes de 268 personas, víctimas de una masacre, mayoritariamente indígenas mayas en la aldea Plan de Sánchez ejecutados por miembros del Ejército en 1982. La Comisión señala que la masacre permanece en la impunidad y que supuestamente el Estado no ha investigado seriamente los hechos, ni juzgado ni sancionado a los responsables, tampoco ha habido reparación. Agrega la Comisión, que los hechos se cometieron en el marco de una política de Estado de genocidio del pueblo maya. El Estado admitió la responsabilidad internacional en el caso. Corte IDH. Caso Masacre Plan de Sánchez vs. Guatemala (2004). Voto razonado juez A. A. Cançado Trindade, párrafo 14. 
nado a los responsables, ni había habido reparación. En este caso, la Corte desarrolla el principio de humanidad, también estudiado por el ex presidente de la Corte Interamericana Pedro Nikken, como un "criterio teleológico de interpretación que podría configurar una suerte de método humanitario, destinado a determinar el alcance de los tratados en la forma más adecuada a su propósito, que es la protección de los derechos fundamentales" ${ }^{20}$. Para el juez Cançado, el trato humano traspasa los límites del Derecho Internacional Humanitario, tanto convencional como consuetudinario: "El derecho internacional contemporáneo (convencional y general) se ha caracterizado en gran parte por la emergencia y la evolución de sus normas imperativas (el jus cogens), y una mayor conciencia, en escala virtualmente universal, del principio de humanidad. Violaciones graves de los derechos humanos, actos de genocidio, crímenes contra la humanidad, entre otras atrocidades, son violadores de prohibiciones absolutas, del jus cogens”. Agrega que, al interpretar y aplicar la Convención, la Corte ha invocado los principios generales del derecho sobre la base del principio de la dignidad de la persona humana y la inalienabilidad de sus derechos: dignidad de la persona que "se identifica con el propio fin del Derecho", y por ese solo hecho debe ser respetada, cualquiera sea la circunstancia. En su análisis el juez aborda el contenido de la cláusula Martens, que actualmente figura en la disposición común sobre denuncia de las cuatro Convenciones de Ginebra ${ }^{21}$, la que "sostiene la aplicabilidad continuada de los principios del derecho de gentes, leyes de humanidad y las exigencias de la conciencia pública, independientemente del surgimiento de nuevas situaciones; la referida cláusula (perteneciente al propio derecho internacional general) impide, pues, el non liquet, y ejerce un rol importante en la hermenéutica de la normativa humanitaria. Las "leyes de humanidad" y las "exigencias de la conciencia pública” por ella invocada recaen en el dominio del jus cogens, la cláusula Martens, como un todo, ha sido concebida y reiteradamente afirmada, en última instancia, en beneficio de todo el género humano, manteniendo así su gran actualidad; se puede considerarla como expresión de razón de la humanidad imponiendo límites a la razón de Estado (raison d'Etat)" 22 .

En el caso Tibi vs. Ecuador, de 2004, la Corte valora la relevancia de la "interpretación evolutiva de los instrumentos internacionales de protección a los derechos humanos" 23 y la considera como una orientación fundamental para fortalecer el avance del Derecho Internacional de los Derechos Humanos.

Por su parte, el Tribunal Europeo de Derechos Humanos, según el estudio del profesor Carrillo Salcedo, también se ha manifestado a favor de la interpretación evoluti-

\footnotetext{
${ }^{20}$ NikKen, Pedro (1987) p. 100.

${ }^{21}$ Convenio de Ginebra III, artículo 142 "Cada una de las Altas partes Contratantes tendrá la facultad de denunciar el presente Convenio".

Párrafo 4: "La denuncia solo será válida para con la Potencia denunciante. No surtirá efecto alguno sobre las obligaciones que las Partes en conflicto hayan de cumplir en virtud de los principios del derecho de gentes, tal como resultan de los usos establecidos entre las naciones civilizadas, de las leyes de humanidad y de las exigencias de la conciencia pública".

22 Caso Masacre Plan de Sánchez vs. Guatemala (2004) voto razonado juez A. A. Cançado Trindade, párrafo 22.

${ }^{23}$ Caso Tibi vs. Ecuador (2004) párrafo 144.
} 
va y dinámica del Convenio Europeo, que, por la particular naturaleza del Convenio, crea obligaciones objetivas que disfrutan de garantía colectiva, y concluye: "el Tribunal ha procedido a interpretar el Convenio con la finalidad de ampliar el alcance de las obligaciones asumidas por los Estados Parte, a fin de dar más alcance a la responsabilidad internacional de estos y brindar mayor protección a los derechos y libertades de las personas sujetas a su jurisdicción"24.

\section{B.2. El DAÑO AL PROYECTO DE VIDA}

En el caso Gutiérrez Soler vs. Colombia, de 2005, la Corte sistematiza la noción: Proyecto de Vida, que ya había introducido en el caso Loayza Tamayo. En este caso, el Estado fue demandado por la detención arbitraria y torturas de Wilson Gutiérrez Soler, actos que le produjeron secuelas persistentes y perturbaciones psíquicas permanentes. La Comisión Interamericana alegó que el proyecto de vida de la víctima fue destruido a raíz de la impunidad y la falta de reparación del daño en las instancias nacionales. Los representantes del demandante denunciaron que los hechos de que fue víctima significaron un cambio radical de su vida cotidiana, provocaron la ruptura de su personalidad y la pérdida de sus lazos familiares ${ }^{25}$. Al respecto, la Corte consideró que los hechos "impidieron la realización de sus expectativas de desarrollo personal y vocacional, factibles en condiciones normales, y causaron daños irreparables a su vida, obligándolo a truncar sus lazos familiares y trasladarse al extranjero, en condiciones de soledad, penuria económica y quebranto físico y psicológico... Asimismo, está probado que la forma específica de tortura que la víctima sufrió no solo ha dejado cicatrices físicas, sino también ha disminuido de manera permanente su autoestima y su capacidad de realizar y gozar de relaciones afectivas íntimas" 26 .

El Tribunal reconoce el daño al proyecto de vida, pero considera que no es posible cuantificarlo en términos económicos. Estima que por tratarse de un daño de naturaleza compleja e integra, requiere como respuesta medidas de satisfacción y garantía de no repetición, que sobrepasan la esfera de lo estrictamente pecuniario. El Tribunal considera que "ninguna forma de reparación podría devolverle o proporcionarle las opciones de realización personal de las que se vio injustamente privado" 27 .

\footnotetext{
24 Carrillo Salcedo (2003) p. 96.

${ }^{25}$ Entre otros hechos, la Corte estima probado:

Que la víctima fue detenida por un coronel de la Policía y su primo (ex teniente coronel de Ejército).

Que el detenido fue conducido a las dependencias del UNASE.

Que fue sometido a torturas, tratos crueles, inhumanos y degradantes para que confesara su participación en un delito.

Que las quemaduras en sus órganos genitales y otras lesiones graves a que fue sometido (establecidas por un médico forense del Instituto Nacional de Medicina Legal, que constató las lesiones) le produjeron secuelas persistentes, y "perturbaciones psíquicas permanentes que fueron evaluadas en el peritaje”.

Que ninguna persona ha sido sancionada por la detención arbitraria y las torturas sufridas por la víctima. Finalmente el Sr. Gutiérrez Soler fue absuelto del delito de extorsión que supuestamente había cometido. Corte IDH. Caso Gutiérrez Soler vs. Colombia (2005).

${ }^{26}$ Caso Gutiérrez Soler vs. Colombia (2005) párrafo 88.

27 Caso Gutiérrez Soler vs. Colombia (2005) párrafo 89.
} 
El daño al proyecto de vida es un derecho aún en desarrollo en la jurisprudencia de la Corte IDH; se desprende de los votos razonados de los magistrados que participaron en la sentencia. Su análisis, en el voto razonado del juez Cançado Trindade, nos introduce en la discusión: "Después de los avances jurisprudenciales sobre el concepto del derecho al 'proyecto' de vida... tenía la Corte la ocasión de avanzar en su construcción al respecto, pero la falta de consenso en el seno de la misma sobre qué rumbo tomar, imposibilitó un nuevo avance. Sin embargo, pienso que la Corte, aun sin unanimidad, debería haber dado un paso adelante en cuanto a su construcción jurisprudencial al respecto, sobre todo ante el paso positivo dado por el Estado demandado de haber aceptado su responsabilidad internacional en el cas d'espéce y de haber pedido perdón a la víctima y sus familiares... El concepto de proyecto de vida tiene, así, un valor esencialmente existencial, atendiéndose a la idea de realización personal integral. Es decir, en el marco transitorio de la vida, a cada uno cabe proceder a las opciones que le parecen acertadas, en el ejercicio de la plena libertad personal, para alcanzar la realización de sus ideales. La búsqueda de la realización del proyecto de vida desvela, pues, un alto valor existencial, capaz de dar sentido a la vida de cada uno" 28 .

El juez afirma que cuando se produce una ruptura forzada, por factores ajenos a la voluntad del hombre, que destruyen su proyecto de vida de manera injusta y arbitraria, el Derecho no puede guardar silencio, más aún cuando este daño suele ser irreparable. Considera que al amparo del artículo 1.1 de la Convención Interamericana, corresponde al Estado respetar y asegurar a todas las personas sujetas a su jurisdicción "la plena vigencia de los derechos protegidos, esencial para la realización del proyecto de vida de cada uno" 29 . Considera que la publicación parcial de la sentencia ordenada por la Corte, como medida de satisfacción adicional para reparar el daño al proyecto de vida y honra de la víctima y sus familiares, podía haber sido seguida de la adopción de nuevas medidas que implicaran "un avance del concepto de derecho al proyecto de vida", cuyo daño "coexiste con el daño moral".

El único voto razonado concurrente de la sentencia es la del juez Oliver Jackman, que plantea sus reservas al concepto de daño al proyecto de vida, pues no comparte la creación de una nueva categoría de daño distinta al daño moral o inmaterial: "Los extensos precedentes que la Corte ha establecido en su jurisprudencia le permiten, sin necesidad de crear un nuevo rubro de reparaciones, evaluar el daño al que se ha hecho referencia y ordenar las medidas pertinentes de acuerdo al artículo 63 de la Convención Americana sobre Derechos Humanos..." ${ }^{30}$. Afirma que la consideración del daño al proyecto de vida es "artificial y una creación que no responde a una necesidad jurídica identificable".

La principal discusión acerca del daño al proyecto de vida, se centra en la actualidad en las medidas de reparación, las que proceden una vez que el daño se ha verificado,

28 Caso Gutiérrez Soler vs. Colombia (2005), voto razonado juez Cançado Trindade, párrafo 3.

29 Caso Gutiérrez Soler vs. Colombia (2005) párrafo 5.

30 Caso Gutiérrez Soler vs. Colombia (2005), voto razonado concurrente juez Oliver Jackman, párrafo 4. 
la Corte ha reiterado en diversos fallos su reconocimiento como categoría autónoma y por lo tanto susceptible de ser verificada ${ }^{31}$.

\section{B.3. LOS FAMILIARES COMO VÍCTIMA}

En el caso Bámaca vs. Guatemala, seguido contra el Estado por la desaparición de Efraín Bámaca el 12 de marzo de 1992 luego de un enfrentamiento entre la guerrilla y el ejército, y donde fue probado que la víctima fue encarcelada de manera secreta en distintas dependencias del ejército, fue torturado y finalmente ejecutado, la Corte recuerda que los familiares de la víctima pueden ser a su vez víctima de una violación. En los casos de desaparición forzada la Corte afirma que la violación del derecho a la integridad de los familiares es una consecuencia directa de la desaparición forzada, ya que genera: "Sufrimiento y angustia, además de un sentimiento de inseguridad, frustración e impotencia ante la abstención de las autoridades públicas de investigar los hechos" 32 .

La Corte se refiere a la jurisprudencia del TEDH, que también ha aceptado que en la violación de los derechos humanos a una persona -especialmente por infracciones al derecho a la vida o integridad personal-, las personas más cercanas también pueden ser consideradas como víctima: "Dicha Corte tuvo la oportunidad de pronunciarse sobre la condición de víctimas de tratos crueles, inhumanos y degradantes de una madre como resultado de la detención y desaparición de su hijo, para lo cual valoró las circunstancias del caso, la gravedad del maltrato y el hecho de no contar con información oficial para esclarecer los hechos. En razón de estas consideraciones, la Corte Europea concluyó que también esta persona había sido víctima y que el Estado era responsable de la violación del artículo 3 de la Convención Europea"33.

En este caso, la Corte retoma lo que ha dicho el TEDH para esclarecer este concepto, y considera: "la proximidad del vínculo familiar, las circunstancias particulares de la relación con la víctima, el grado en el cual el familiar fue testigo de los eventos relacionados con la desaparición, la forma en que el familiar se involucró respecto a los intentos de obtener información sobre la desaparición de la víctima, y las respuestas

\footnotetext{
${ }^{31}$ Caso Loayza Tamayo vs. Perú (1997). Caso Cantoral Benavides vs. Perú (2000). Caso Maritza Urrutia vs. Guatemala (2003). Caso Myrna Mack Chang vs. Guatemala (2003). Caso Tibi vs. Ecuador (2004). Caso "Instituto de Reeducación del Menor" vs. Paraguay (2004).

${ }^{32}$ La denuncia señaló que Efraín Bámaca desapareció el 12 de marzo de 1992, luego de un enfrentamiento entre la guerrilla y el ejército. La víctima fue encarcelada de manera secreta en distintas dependencias del ejército donde habría sido torturada y finalmente ejecutada.

La Comisión puso en conocimiento de la Corte una demanda en contra del Estado de Guatemala para establecer si dicho Estado violó en perjuicio de Efraín Bámaca Velásquez las siguientes normas:

Artículo 3 (derecho al reconocimiento de la personalidad jurídica), artículo 4 (derecho a la vida), artículo 5 (derecho a la integridad personal), artículo 7 (derecho a la libertad personal), artículo 8 (garantías judiciales), artículo 13 (libertad de pensamiento y de expresión), artículo 25 (protección judicial) y el artículo1 (obligación de respetar y garantizar los derechos), todos de la Convención Americana, así como los artículos 1, 2, 6 de la Convención Interamericana para Prevenir y Sancionar la Tortura, y el artículo 3 común de los Tratados de Ginebra. Corte IDH. Caso Bámaca Velásquez vs. Guatemala (2000).

${ }^{33}$ Caso Bámaca Velásquez vs. Guatemala (2000), párrafo 162.
} 
ofrecidas por el Estado a las gestiones incoadas"34. La Corte valoró la "continua obstrucción a los esfuerzos de Jennifer Harbury [cónyuge de Efraín Bámaca] por conocer la verdad de los hechos, y sobre todo el ocultamiento del cadáver de Bámaca Velásquez y los obstáculos que interpusieron diversas autoridades públicas a las diligencias de exhumación intentadas, así como la negativa oficial de brindar información al respecto" 35 .

La Corte consideró que la cónyuge fue sometida a tratos crueles inhumanos y degradantes. Respeto al padre y hermanas de la víctima, estima que la "falta de conocimiento sobre el paradero de Bámaca Velásquez causó una profunda angustia en los familiares de este..."36. En consecuencia, consideró que su padre y hermanas fueron víctimas de una violación a los artículos 5.1 y 5.2 de la Convención.

La sentencia cuenta con el voto razonado del juez Sergio García Ramírez que analiza la evolución del concepto de víctima, fundamental para identificar al "sujeto pasivo de la lesión” y, por sus consecuencias procesales, para determinar la legitimación y "capacidad de actuación" en las diversas etapas del proceso. En cuanto a la víctima -desde lo que originalmente se consideró víctima directa hasta ampliar su noción a la víctima indirecta y potencial-, el juez dice que este desarrollo "revela claramente el impulso tutelar del derecho internacional de los derechos humanos, que pretende llevar cada vez más lejos -en una tendencia que estimo pertinente y alentadora- la protección real de los derechos humanos. El principio favorecedor de la persona humana, que se cifra en la versión amplia de la regla pro homine -fuente de interpretación e integración progresiva- tiene aquí una de sus mas notables expresiones" 37.

El análisis del daño se estructura sobre la distinción de la afectación de los derechos de Efraín Bámaca, por una parte, y por la otra, la vulneración de los derechos de sus familiares. En esta lógica es obvio que hubo violaciones que afectaron directamente al Sr. Bámaca, y otras a su cónyuge y familiares, que además se vieron afectados por las violaciones que afectaron al primero. Propone una definición de víctima directa, como aquella "que sufre menoscabo de sus derechos fundamentales como efecto inmediato de la propia violación: entre esta y aquel existe una relación de causa a efecto (en sentido jurídico del vínculo), sin intermediario ni solución de continuidad"38. Mientras que víctima indirecta es aquella "que experimenta el menoscabo en su derecho como consecuencia inmediata y necesaria, conforme a las circunstancias, del daño que sufrió la víctima directa" 39 . Afirma que la distinción no tiene efectos en una mayor jerarquía para los fines de la tutela jurídica, ambas son reconocidas por la Convención como acreedores de reparación, ni tampoco es relevante para atribuirles legitimación procesal.

En cuanto a la prueba del daño, en el caso de los familiares, la sentencia de Reparaciones del caso Bámaca Velásquez, estima que los padecimientos sufridos por

\footnotetext{
${ }^{34}$ Caso Bámaca Velásquez vs. Guatemala (2000) párrafo 163.

${ }^{35}$ Caso Bámaca Velásquez vs. Guatemala (2000) párrafo 165.

36 Caso Bámaca Velásquez vs. Guatemala (2000) párrafo 165.

37 Caso Bámaca Velásquez vs. Guatemala (2000) voto razonado concurrente, juez Sergio García Ramírez, párrafo 3.

${ }^{38}$ Caso Bámaca Velásquez vs. Guatemala (2000) párrafo 5.

${ }^{39}$ Caso Bámaca Velásquez vs. Guatemala (2000) párrafo 5.
} 
Efraín Bámaca "se extienden de igual manera a los miembros más íntimos de la familia, particularmente aquellos que tuvieron un contacto afectivo estrecho con la víctima. La Corte considera que no se requiere prueba para llegar a la mencionada conclusión, aunque en el presente caso se encuentre probado el sufrimiento ocasionado a aquellos" 40 . En lo que respecta al padre, la Corte reitera que "no es necesario demostrar el daño inmaterial", y respecto a sus hermanas es "razonable presumir que como miembros de la familia no debieron ser indiferentes a la pérdida de su hermano" ${ }^{41}$.

En el caso Myrna Mack Chang vs. Guatemala, de 2003, iniciado por la ejecución extrajudicial de la antropóloga Myrna Mack, la Corte ratifica el criterio que atribuye la condición de víctima a los familiares. La Corte toma en cuenta los sufrimientos de los familiares provocados por "las amenazas, seguimientos, hostigamientos, e intimidaciones de que han sido objeto como métodos para impedir que sigan impulsando la búsqueda de la justicia a fin de sancionar a los responsables de la ejecución" ${ }^{2}$. La Corte dice, "En el caso sub judice, se ha demostrado, pues, una violación de la integridad personal de los familiares inmediatos de la víctima como consecuencia directa de las amenazas y hostigamientos sufridos por estos desde el inicio de la investigación por la ejecución extrajudicial de Myrna Mack Chang. Esta situación se ha visto agravada por el patrón de obstrucciones de las investigaciones... el asesinato de un policía investigador, las amenazas y hostigamientos sufridos por algunos de los operadores de justicia, policías, testigos, ante lo cual se vieron forzados a exiliarse" 43 . Todos estos hechos han provocado en los familiares de Myrna Mack angustia, sentimientos de frustración, impotencia y temor. Y en consecuencia estima que los familiares han sido a su vez víctimas de violación al artículo 5.1.

En cuanto al deber de reparación, reitera que no es necesario probar el daño e incluso lo extiende a una hermana de la víctima, pese a no haberse hecho parte en el proceso, alejándose con ello de los criterios sostenidos por el TEDH, que exige que el familiar haya mostrado cierta actividad en la investigación de los hechos ${ }^{44}$. Para fijar la compensación a los familiares, la Corte considera dos aspectos: el primero, en relación al sufrimiento que padecieron por el asesinato de su familiar; el segundo se refiere a los hostigamientos y amenazas de que ellos fueron víctima después de la muerte de su familiar, además de la impunidad que ha imperado en este caso, que constituye una fuente de sufrimiento y angustia permanente.

\footnotetext{
${ }^{40}$ Caso Bámaca Velásquez vs. Guatemala (2002) Guatemala, Sentencia de Reparaciones de 22 de febrero de 2002, párrafo 63.

${ }^{41}$ Caso Bámaca Velásquez vs. Guatemala (2000) párrafo 65 letra c).

${ }^{42}$ La Comisión sometió a consideración de la Corte si el Estado violó los artículos 4 (Derecho a la vida), 8 (Garantías Judiciales), 25 (Protección Judicial) en conjunto con el artículo 1.1 (Obligación de Respetar los Derechos) de la Convención Americana, en perjuicio de Myrna Elizabeth Mack Chang y sus familiares por su ejecución extralegal ocurrida el 11 de septiembre de 1990. Asimismo la Comisión solicitó que se ordene al Estado para que se procediera a las reparaciones pecuniarias y no pecuniarias que correspondieren. Corte IDH. Caso Myrna Mack Chang vs. Guatemala (2003) párrafo 226.

${ }^{43}$ Caso Myrna Mack Chang vs. Guatemala (2003) párrafo 232.

${ }^{44}$ Caso Çakici contra Turkía (1999) párrafos 98-99.
} 
El voto concurrente razonado del juez Sergio García Ramírez, aborda el contenido de la expresión "familiares": "el Reglamento del año 2000 -cuarto Reglamento en la historia de la Corte Interamericana-, que ha ensanchado el papel de los particulares ante el tribunal, aproximando cada vez más -hasta donde lo permite el marco procesal del Pacto de San José- la parte material y la parte procesal, incorporó referencias a los familiares. Esta voz significa "los familiares inmediatos, es decir, ascendientes y descendientes en línea directa, hermanos, cónyuges o compañeros permanentes, o aquellos determinados por la Corte en su caso" (que pudieran estar vinculados con la víctima directa e inmediata por una relación de parentesco más o menos cercana, y por motivos de afecto y convivencia que llevan a tratarlos con la misma relevancia y las mismas consecuencias que corresponden a esos otros "familiares inmediatos)" 45.

Distinguimos en el tratamiento de la víctima en casos por desaparición forzada, diferencias con lo que concluye el TEDH respecto a los familiares de la víctima. El Tribunal de Estrasburgo exige una cierta actividad o acciones destinadas a investigar el paradero de la víctima, mientras que para la Corte esta actividad no es necesaria, no exige acreditar el daño, lo presume.

\section{B.4. OTRAS MEDIDAS DE REPARACIÓN}

En este apartado trataremos el contenido de la reparación en lo que la Corte ha venido denominando "otras reparaciones", es decir, medidas de carácter innovador, que implican una obligación de hacer, concedidas por la Corte a propósito de la valoración del daño que analiza de modo integral.

En tanto obligación de hacer, si existe una cuestión atrayente en lo que se refiere a la obligación positiva que se deriva de la Convención Interamericana de Derechos $\mathrm{Hu}-$ manos, es que, a diferencia de lo que ocurre en el ámbito del derecho interno donde no existen mecanismos constitucionales para reclamar la intervención del Estado, esto sí es posible en el ámbito de los tribunales internacionales de derechos humanos. Recordemos el artículo 63.1 de la Convención Americana: "Cuando se decida que hubo violación de un derecho o libertad protegidos en esta Convención, la Corte dispondrá que se garantice al lesionado en el goce de su derecho o libertad conculcado. Dispondrá asimismo, si ello fuera procedente, que se reparen las consecuencias de la medida o situación que ha configurado la vulneración de esos derechos y el pago de una justa indemnización a la parte lesionada”.

La doctrina de las "obligaciones positivas" 46 creada por el Tribunal Europeo de Derechos Humanos y la Corte Interamericana con sus reiteradas condenas a los Estados

${ }^{45}$ Caso Myrna Mack Chang vs. Guatemala (2003), voto razonado concurrente, juez Sergio García Ramírez, párrafo 54.

46 "Se trata de una construcción jurisprudencial del Tribunal de Estrasburgo, sin base textual expresa en el Convenio Europeo de Derechos Humanos. La idea básica es, de nuevo, que a veces la efectividad de los derechos fundamentales requiere cierta colaboración por parte de los poderes públicos. El derecho a la vida privada... ha sido particularmente fértil para las obligaciones positivas. Así se ha considerado atentatorio contra el derecho a la vida privada: la falta de legislación protectora del hijo extramatrimonial (STEDH Marckx c. Bélgica de 13 de junio de 1979)...”. DíEZ-PiCAZO (2005) p. 122. 
por infracción de obligaciones de hacer, se vincula al hecho que los tribunales internacionales de derechos humanos, en general, examinan la responsabilidad de los Estados en base a resultados y no a medios.

En la sentencia de reparaciones del caso Loayza Tamayo, seguido contra el Estado peruano por la detención ilegal y las torturas que la profesora Loayza Tamayo sufrió durante su incomunicación y privación de libertad, la Corte ordenó que el Estado tomara medidas para reincorporar a la víctima al servicio docente al que pertenecía antes de su detención; asegurarle el derecho al goce de jubilación; y adoptar medidas para evitar posibles efectos adversos de las resoluciones dictadas contra la víctima ante el fuero civil. Asimismo, la Corte trató el daño al proyecto de vida y aunque considera que este se ha producido, no le traduce en reconocimiento económico, por tanto, se abstiene de cuantificarlo. Por el contrario, en el caso Cantoral Benavides, también seguido contra Perú por la detención ilegal y tortura de Luis Alberto Cantoral, en sentencia de reparaciones de 3 de diciembre de 2001, la Corte considera probado que los hechos que afectaron a Luis Alberto Cantoral dañaron su proyecto de vida y en consecuencia ordena, para restablecerlo, que el Estado proporcione a la víctima una "beca de estudios superiores o universitarios”. Esta será la primera sentencia donde la Corte accede a una medida de esta naturaleza por daño al proyecto de vida. En cuanto a la sentencia de la Corte Suprema del Perú, que condenó a Luis Alberto Cantoral, puesto que la normativa en que ella se basó era incompatible con la Convención, ordena al Estado que la "deje sin efecto alguno", y proceder en consecuencia, anulando los antecedentes penales, administrativos, judiciales o policiales que existan en su contra. Asimismo, ordena una medida de satisfacción y garantía de no repetición -reiterada en su posterior jurisprudencia- mediante la publicidad de la sentencia. Por tanto, ordena al Estado publicar, tanto en el Diario Oficial como en otro de circulación nacional, la parte resolutiva de la sentencia de fondo ${ }^{47}$.

En el caso Tibi vs. Ecuador, la Corte ordena, además de investigar los hechos de que fue víctima el Sr. Tibi y sancionar a sus responsables, que los resultados de esa investigación sean públicamente difundidos; dispone la publicación en el Diario Oficial y en un periódico de circulación nacional, de determinados aspectos de la parte resolutiva de la sentencia de fondo. Igualmente, reitera el deber del Estado de "hacer pública una declaración escrita formal emitida por las altas autoridades del Estado en la que reconozca su responsabilidad internacional por los hechos a que se refiere el presente caso y pida disculpas al Sr. Tibi y las demás víctimas..."48. Además de las medidas de publicidad, la Corte ordena al Estado que establezca un programa de formación sobre principios y normas de protección a los derechos humanos, que incluya recursos para su ejecución y que se realice en conjunto con la sociedad civil, dirigido a operadores de justicia, personal del Ministerio Público, personal policial, penitenciario y expertos en salud mental.

\footnotetext{
${ }^{47}$ Caso Cantoral Benavides vs. Perú (2001). Reparaciones (art. 63.1 Convención Americana sobre Derechos Humanos). .

${ }^{48}$ Caso Tibi vs. Ecuador (2004) párrafo $280 \mathrm{~N}^{\circ} 12$.
} 
En el caso Gutiérrez Soler vs. Colombia, de 2005, en cuanto otras posibles formas de reparación, la Corte dispone medidas que atienden al daño inmaterial sin alcance pecuniario, y reitera la orden de dar publicidad al proceso que se abra para investigar los hechos, de manera que la "sociedad colombiana pueda conocer la verdad acerca de los hechos de este caso" ${ }^{49}$. Asimismo, exige al Estado brindar asistencia psicológica a la víctima y sus familiares; reitera el deber de publicar determinados aspectos de la sentencia. Por otra parte, frente a los compromisos del Estado demandado, la Corte valora y acoge con satisfacción la voluntad expresada por el Estado de incluir en sus cursos de formación a funcionarios públicos, información sobre jurisprudencia y estándares internacionales de acceso a la justicia: "Al respecto, el Tribunal considera que el Estado debe implementar los cursos de formación de los servidores públicos de la jurisdicción militar y de la fuerza pública un programa dirigido al análisis de la jurisprudencia del Sistema Interamericano de Protección de los Derechos Humanos en relación con los límites de la jurisdicción penal militar, así como los derechos a las garantías judiciales y la protección judicial, como forma de prevenir que casos de violación a los derechos humanos sean investigados y juzgados por dicha jurisdicción" ${ }^{0}$. Además, ordena la "implementación de los parámetros del Manual para investigación y documentación eficaces de la tortura y otros tratos o penas crueles, inhumanos o degradantes (el Protocolo de Estambul) ${ }^{51}$. Por último, y por primera vez, la Corte se refiere de manera expresa a la necesidad de que, junto con el estudio de su jurisprudencia, el Estado tome medidas para que sus criterios "y los precedentes de la Corte Constitucional de Colombia respecto del fuero militar sean aplicados de manera efectiva en el ámbito interno" 52 .

\section{CONCLUSIONES}

En el marco del reconocimiento voluntario de la competencia de la Corte Interamericana para conocer de denuncias por violaciones a los derechos humanos, se ha activado en la región un mecanismo que busca restablecer su vigencia y resarcir a víctimas por las graves violaciones a sus derechos que, pese a sus limitaciones, ha introducido mediante la interpretación evolutiva de los instrumentos internacionales, la preeminencia del respeto por los derechos humanos a todas las personas y en cualquier situación.

En el desarrollo jurisprudencial del tratamiento de la víctima, la concepción progresiva del Derecho Internacional de los Derechos Humanos es uno de los elementos sobre el cual la Corte sustenta sus criterios. No en el sentido de crear nuevos derechos, sino en tanto les protege de mejor modo.

El daño al proyecto de vida, reconocido por la Corte como una categoría independiente del daño material e inmaterial, representa una de las perspectivas más interesantes

\footnotetext{
${ }^{49}$ Caso Gutiérrez Soler vs. Colombia (2005) párrafo 96.

${ }^{50}$ Caso Gutiérrez Soler vs. Colombia (2005) párrafo 106.

51 Caso Gutiérrez Soler vs. Colombia (2005) letra e).

52 Caso Gutiérrez Soler vs. Colombia (2005) párrafo 108.
} 
en el trabajo de la Corte IDH. Si bien, aún no se aprecia unanimidad entre los jueces en cuanto a la reparación del daño al proyecto de vida, la Corte ha señalado reiteradamente que se trata de una categoría autónoma, determinada por la responsabilidad del Estado y que se produce cuando una violación a los derechos humanos altera las posibilidades de desarrollo de una persona, no en cuanto a lo que dejó de percibir como consecuencia de la violación, sino respecto a lo que ella pudo ser, a sus posibilidades de hacer de su vida un medio para la felicidad o satisfacción personal.

En el tratamiento de los familiares como víctima de la violación, la Corte ha mostrado una posición más amplia que la sostenida por el Tribunal Europeo. La Corte Interamericana presume que el daño producido a la víctima de una violación se extiende a su familia (en un sentido amplio) y no exige que ese sufrimiento sea acreditado en el proceso, ya que lo supone.

El respeto de los derechos humanos, además de una obligación de no hacer, supone para los Estados obligaciones de hacer que se expresan en el deber de prevenir, investigar y sancionar cualquier violación a los derechos humanos. Las nuevas medidas de reparación ponen énfasis en la reparación del daño a través de medidas como la obligación de dar asistencia psicológica a la víctima, dar publicidad a los contenidos de la sentencia y al reconocimiento de la responsabilidad del Estado por los actos que le han afectado. Estas medidas son igualmente una suerte de "garantía de no repetición de los actos" cuando la Corte ordena instruir y capacitar a los funcionarios públicos acerca del correcto tratamiento de los detenidos, o difundir sus criterios jurisprudenciales en casos de tortura, y tratos o penas crueles inhumanas o degradantes.

El nuevo desafío para la Corte Interamericana y los actores a favor de los derechos humanos del continente, es ahora definir y establecer los mecanismos que aseguren la recepción en el derecho interno de su doctrina, labor que debe ir acompañada de la voluntad real y efectiva de los Estados americanos para avanzar en un modelo de protección que, pese a todas sus imperfecciones, es hasta ahora el que con más decisión ha venido a amparar a las víctimas de las más graves violaciones a los derechos humanos ocurridas en nuestro continente.

\section{BIBLIOGRAFÍA CITADA}

Carillo Salcedo, Juan Antonio (2003): El Convenio Europeo de Derechos Humanos (Madrid, Ed. Tecnos) 156 pp.

DíEZ- PiCAzO, Luis María (2005): Sistema de Derechos Fundamentales (Navarra, Editorial Arazandi) 566 pp.

Nikken, Pedro (1987): La Protección Internacional de los Derechos Humanos, su Desarrollo Progresivo (Madrid, Editorial Civitas S.A.) $321 \mathrm{pp}$.

\section{JURISPRUDENCIA CITADA}

Bámaca Velásquez vs. Guatemala (2000): Corte IDH., 25 de noviembre de 2000, Serie C $\mathrm{N}^{\circ} 70$. 
Bámaca Velásquez vs. Guatemala (2002): Corte IDH., 22 de febrero de 2002, Reparaciones (art. 63.1 Convención Americana sobre Derechos Humanos). Serie C No 91.

Cantoral Benavides vs. Perú (2000): Corte IDH., 18 de agosto de 2000, Serie C Nº 69.

Cantoral Benavides vs. Perú (2001): Corte IDH., 3 de diciembre de 2001, Reparaciones (art. 63.1 Convención Americana sobre Derechos Humanos). Serie C No 88.

Gutiérrez Soler vs. Colombia (2005): Corte IDH., 12 de septiembre de 2005, Serie C N ${ }^{\circ}$ 132.

Hermanos Gómez Paquiyauri vs. Perú (2004): Corte IDH., 8 de julio de 2004, Serie C $\mathrm{N}^{\circ} 110$.

Hilaire vs. Trinidad y Tobago (2001): Corte IDH., 1 de septiembre de 2001, Excepciones preliminares, Serie $\mathrm{C} \mathrm{N}^{\circ} 80$.

Instituto de Reeducación del Menor vs. Paraguay (2004): Corte IDH., 2 de septiembre de 2004, Serie C N 112.

Masacre Plan de Sánchez vs. Guatemala (2004): Corte IDH., 29 de abril de 2004, Serie $\mathrm{C} \mathrm{N}^{\circ} 105$

Myrna Mack Chang vs. Guatemala (2003): Corte IDH, 25 de noviembre de 2003, Serie $\mathrm{C} \mathrm{N}^{\circ} 101$.

Tamaya vs. Perú (1997): Corte IDH., 17 de septiembre de 1997. Serie C N³3, Reparaciones, Sentencia de 27 de noviembre de 1998 (art. 63.1 Convención Americana sobre Derechos Humanos).

Tibi vs. Ecuador (2004): Corte IDH., 7 de septiembre de 2004, Serie C N 114.

Urrutia Maritza vs. Guatemala (2003): Corte IDH, 27 de noviembre de 2003. 
